\title{
Effective Removal of Bisphenol a from Contaminated Areas by Recombinant Plant Producing Lignin Peroxidase
}

Tomonori Sonoki $^{1 *}$, Shinya Kajita ${ }^{2}$, Mikiko Uesugi ${ }^{2}$, Yoshihiro Katayama ${ }^{2}$ and Yosuke limura ${ }^{3}$

${ }^{1}$ Faculty of Agriculture and Life Science, Hirosaki University, 3 Bunkyo-cho, Hirosaki, Aomori 036-8561, Japan

${ }^{2}$ Graduate School of Bio-Applications and Systems Engineering, Tokyo University of Agriculture and Technology, Koganei, Tokyo 184-8588, Japan

${ }^{3}$ Institute for Environmental Management Technology, National Institute of Advanced Industrial Science and Technology, 16-1 Onogawa, Tsukuba, Ibaraki 305-0053, Japan

\begin{abstract}
We have attempted to enhance the environmental decontamination functions of plants by introducing appropriate enzymatic activities from microorganisms. Lignin peroxidase is a well-known enzyme used for the degradation of some environmental pollutants. In the present study, we introduced an extracellular fungal enzyme, the lignin peroxidase of Trametes versicolor, into tobacco plants. Six transgenic plant, designated FLP-1, 2, 3, 4, 5 and 8 , produced lignin peroxidase in a crude extract of the root. The FLP-1, FLP-2 and FLP-8 were able to remove 10umol of bisphenol A $\mathrm{g}^{-1}$ dry weight from hydroponic culture. The efficiency of this removal was approximately 4-fold greater than that of control lines. Our results should stimulate efforts to develop plant-based technologies for the removal of environmental pollutants from contaminated environments.
\end{abstract}

Keywords: Phytoremediation; Lignin peroxidase; Bisphenol A

Abbreviations: Lip: gene product of flip of Trametes versicolor IFO1030; BPA: bisphenol A; CaMV: cauliflower mosaic virus

\section{Introduction}

There have been several reports that fungal lignin-degrading enzymes such as manganese peroxidase, laccase and lignin peroxidase (LiP) can degrade or polymerize toxic organic chemicals such as polychlorophenols, polycyclic aromatic hydrocarbons and chlorinated aromatic compounds [1-3]. In the present study, we focused on the removal of bis-phenol A (BPA; 2,2-bis(4-hydroxyphenyl)propane), one of the major chemicals used in plastics and resins and a wellknown disruptor of endocrine function in humans and animals, from contaminated areas using fungal lignin-degrading enzymes.

In recent years, phytoremediation technology has gained attention as an ecological remediation tool for contaminated soil and water. Plants can be grown autotrophically, so that making the phytoremediation technology is a suitable strategy for the continuous remediation and maintenance of widely contaminated areas. There have been many reports of phytoremediation using transgenic plants. Transgenic plants that overexpress mercury-resistance genes have been found to be highly resistant to organic mercury and are effective for degradation [4]. In addition, glutathione-S-transferase- and cytochrome P-450-expressing transgenic plants have elevated resistance to pesticides [5,6]. Introducing bacterial genes, which encode enzymes involved in the degradation of poly-chlorinated biphenyl (PCB), into plants has shown potential for effective PCB removal [7]. Some reports have shown previously that manganese peroxidase and laccase-expressing transgenic tobaccos are able to effectively remove environmental pollutants such as BPA and pentachlorophenol $[8,9]$. Appropriately engineered plants have great potential as tools for the remediation of contaminated soil and water.

In this study, we introduced lignin peroxidase (LiP) from Trametes versicolor into Nicotiana tabacum. To our knowledge, this is the first report of transgenic tobaccos expressing LiP. We discussed discuss herein the production of LiP in plants and the removal ability of BPA during hydroponic cultivation.

\section{Materials and Methods}

\section{Plants and microorganisms used in this study}

We used leaf disks of tobacco (N. tabacum Sumsun NN) plants for the generation of transgenic plants; Escherichia coli JM109 and E. coli HB101 (Takara Bio Inc., Shiga, Japan) as host cells for the manipulation of DNA; and T. vercicolor IFO1030 for the isolation of cDNA that encodes flip.

\section{Isolation of the flip gene from $T$. versicolor IFO1030 and construction of a binary vector}

To isolate a cDNA encoding LiP from T. versicolor IFO1030, we used conserved amino acids in the reported sequences of $\mathrm{LiP}$ from $T$. versicolor (Accession no. M64993) [10], Phanerochaete chrysosporium (L08963) and Phlebia radiata (X14446) [11, 12]. Among them, we selected two conserved nucleic acid sequences for the synthesis of primers for polymerase chain reaction (PCR). The primer sequences were 5'-CGAGACIRMMTTCCACCCCAACAT-3' and 5'ARRSTSGGGAAGGGGGTCTCG-3', and amplification of a partial fragment of LiP cDNA was performed with Pyrobest DNA polymerase (TaKaRa Bio Co., Shiga, Japan), using as a template the pool of firststrand cDNA that had been prepared by reverse transcription of total RNA from mycelia of T. versicolor. An amplified product of the expected size (about $750 \mathrm{bp}$ ) was purified by agarose electrophoresis and then extracted from the gel for confirmation of its nucleotide sequence. Based on the nucleotide sequence of this amplified fragment, a fulllength cDNA that included the amplified fragment was obtained by 5 -

*Corresponding author: Tomonori Sonoki, Faculty of Agriculture and Life Science, Hirosaki University, 3 Bunkyo-cho, Hirosaki, Aomori 036-8561, Japan Tel: +81-172-39-3585; E-mail: sonoki@cc.hirosaki-u.ac.jp

Received January 25, 2011; Accepted January 25, 2011; Published February 01, 2011

Citation: Sonoki T, Kajita S, Uesugi M, Katayama Y, limura Y (2011) Effective Removal of Bisphenol a from Contaminated Areas by Recombinant Plant Producing Lignin Peroxidase. J Pet Environ Biotechnol 2:105. doi:10.4172/2157-7463.1000105

Copyright: ( 2011 Sonoki T, et al. This is an open-access article distributed under the terms of the Creative Commons Attribution License, which permits unrestricted use, distribution, and reproduction in any medium, provided the original author and source are credited. 
RACE and 3'-RACE methods [13]. Full-length cDNA for LiP from T. versicolor was then cloned into pCR2.1 (Invtrogen Co., Calif, USA), and its nucleotide sequence was confirmed.

To obtain the LiP cDNA sequence including Xba I and Bam HI sites, we synthesized one set of primers for PCR, 5'ATGCTCTAGAATGGCCTTCAAAACCTTACTCTCCA-3' and 5'ATGCGGATCCTCACGGAAGGGGGACGGGGGCGACA -3’. After amplification of the cDNA fragment encoding the LiP protein that included a signal peptide by PCR, the CDNA was digested with the appropriate restriction enzymes and cloned between the Xba I and Bam HI sites of the binary vector pBI121 with double cauliflower mosaic virus (CaMV) 35S promoter sequence (pWP/pBI121). The resulting tumor-induced (Ti) plasmid was designated pWPflip (Figure 1).

\section{Transformation of N. tabacum Samsun NN}

We introduced the T-DNA region of pWPflip into the genome of tobacco by the leaf-disk method using Agrobacterium tumefaciens LBA4404 [14]. We also produced control transgenic plants by transformation with the parental plasmid $\mathrm{pWP} / \mathrm{pBI} 121$. Plants resistant to kanamycin $\left(150 \mu \mathrm{g} \mathrm{L}^{-1}\right)$ that had been regenerated from leaf disks were transferred to MS medium [15] that contained 30 $\mathrm{g} \mathrm{L}^{-1}$ sucrose and $100 \mu \mathrm{g} \mathrm{L}^{-1}$ kanamycin for incubation and growth in a growth chamber at $25^{\circ} \mathrm{C}$. Integration of flip cDNA into the genome of kanamycin-resistant transgenic tobacco was confirmed by PCR with primers, 5'-GCTTCTTCGCCTTACGTTCCA-3' and 5'-GCGAGTTGATGTCCTGGCCGAA-3'.

\section{Detection of LiP production in the roots of $\mathrm{LiP}$ transgenic plants}

Each transgenic tobacco was incubated on MS medium containing $30 \mathrm{~g} \mathrm{~L}^{-1}$ and $100 \mu \mathrm{g} \mathrm{L}^{-1}$ kanamycin for 2 months and then cell free extracts were prepared from the roots of each plant. The roots were weighed in a $2 \mathrm{~mL}$ tube and were disrupted with Multi-BeadsShocker (Yasui Kikai Co., Osaka, Japan). Crushed root aliquots were suspended with $0.2 \mathrm{~mL}$ of $50 \mathrm{mM}$ Tris- $\mathrm{HCl}$ buffer $(\mathrm{pH} 8.0)$ and placed at $4^{\circ} \mathrm{C}$ for $10 \mathrm{~min}$. After centrifugation, the supernatant was collected as cell free extracts. The extracts were assayed with a protein assay kit (Bradford type of reagent. Bio-Rad Laboratories, Inc., Calif, USA). $50 \mathrm{mg}$ of protein extracted from roots of $\mathrm{LiP}$ transgenic tobaccos was separated by electrophoresis on an sodium dodecyl sulphate polyacrylamide gel (SDS-PAGE) and transferred onto polyvinylidene fluoride (PVDF) membranes. Immunodetection was performed with a biotin-streptavidin-alkaline phosphatase system and Lip-specific antiserum. To produce antiserum against the LiP protein of $T$. versicolor IFO1030, the sequence CNGTTFPGTGDNQGE (between 240 and 254) was selected as the epitope. The peptide of the epitope was synthesized and conjugated with keyhole limpet hemocyanin (KLH). The resultant peptide-KLH conjugant was injected into a 10 -wk-old rabbit. After four injections, antiserum was collected and used for Western blot analysis.

\section{BPA reduction by hydroponiccally cultured lignin peroxidase producing tobacco plants}

The LiP-producing transgenic plants were incubated for 2 months on MS medium containing $30 \mathrm{~g} \mathrm{~L}^{-1}$ of sucrose and $100 \mu \mathrm{g} \mathrm{L}^{-1}$ of kanamycin. Each transgenic plant was transferred to $100 \mathrm{~mL}$ of fresh MS liquid medium containing $3 \mathrm{~g} \mathrm{~L}^{-1}$ of sucrose and $100 \mu \mathrm{g} \mathrm{L}^{-1}$ of kanamycin. After further incubation of 1 week at $25^{\circ} \mathrm{C}, 10 \mu \mathrm{mol}$ of BPA (final $100 \mu \mathrm{M}$ ) was added to $100 \mathrm{~mL}$ of medium, and plants were maintained in hydroponic culture for another week. A $1 \mathrm{~mL}$ sample of hydroponic culture was centrifuged at $10,000 \mathrm{~g}$ for $5 \mathrm{~min}$, and a $100 \mu \mathrm{L}$ portion of the supernatant was subjected to HPLC analysis with a Waters Alliance system (Waters Co., CA, USA). Chromatographic separations were performed with a Puresil $\mathrm{C}_{18}$ cartridge column (length, $150 \mathrm{~mm}$; id, $4.6 \mathrm{~mm}$; Waters Co.). The mobile phase consisted of a mixture of $1 \%$ phosphoric acid and acetonitrile $(65: 35, \mathrm{v} / \mathrm{v})$, and the flow rate was 1.0 $\mathrm{mL} \min ^{-1}$. The column oven temperature kept at $40^{\circ} \mathrm{C}$.

\section{Results and Discussion}

\section{Isolation of flip cDNA and production of $\mathrm{LiP}$ transgenic tobaccos}

We isolated a cDNA encoding LiP from T. versicolor IFO 1030 by PCR as described in Materials and Methods. The nucleotide sequence of the cDNA was confirmed. The deduced amino acid sequences were 84.9 and $59.2 \%$ homologous, respectively, to those of LiP of T. versicolor (Accession No. M644933) and P. crysosporium (L08963). The peroxidase active site signature motif $\left({ }_{67} \mathrm{~A}\right.$-HESLRLTFHD $\left.-{ }_{78} \mathrm{~A}\right)$ was conserved in the deduced amino acid sequence of the cDNA, namely flip.

We introduced the flip gene, which included the signal peptide sequence, under the control of a double $35 \mathrm{~S}$ promoter sequence from CaMV into the genome of tobacco by the leaf-disk methods via $A$. tumefacience LBA4404. Control transgenic plants were also produced by transformation with $\mathrm{pWP} / \mathrm{pBI} 21$. Kanamycin $\left(150 \mu \mathrm{g} \mathrm{L} \mathrm{L}^{-1}\right)$-resistant plants that had regenerated from leaf disks were transferred to MS medium containing $30 \mathrm{~g} \mathrm{~L}^{-1}$ of sucrose and $100 \mu \mathrm{g} \mathrm{L}^{-1}$ of kanamycin in pots for incubation and grown in a growth chamber at $25^{\circ} \mathrm{C}$. Integration of flip cDNA into the genome of tobacco was confirmed by PCR upon 10 independent kanamycin-resistant transgenic plants. Two of the LiP transgenic tobaccos, FLP-6 and FLP-9, showed obvious inhibition of growth and were therefore excluded from this study. All tested 8 transgenic plants harbored flip cDNA in their genomes (Figure 2).

\section{LiP production in the roots of transgenic plants}

To confirm the production of LiP protein in the roots of transgenic plants, we performed Western blot analysis with root extracts of transgenic plants and antiserum raised against the KLH-conjugated

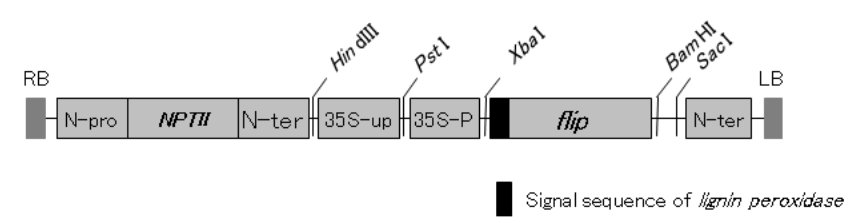

Figure 1: T-DNA region of the Ti plasmid pWPflip. RB: Right T-DNA border, N-pro: promoter region of nopaline synthase gene, NTPIl: neomycin phosphotransferase gene, $\mathrm{N}$-ter: terminator region of nopaline synthase gene, 35S-up: upstream region of the cauliflower mosaic virus (CaMV) $35 \mathrm{~S}$ promoter sequence, 35S-P: CaMV $35 S$ promoter sequence, flip: CDNA encoding lignin peroxidase of Trametes versicolor IFO1030 plus signal sequence, LB: left T-DNA border.

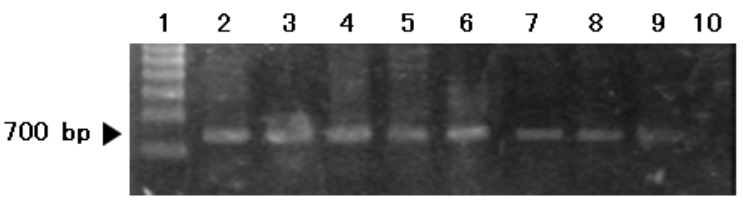

Figure 2: Analysis of cvlip integration by PCR. Amplified fragments (about $700 \mathrm{bp}$ ) were observed in all tested 8 transgenic lines. Lanes; 1,500 bp DNA Ladder Marker; 2, FLP-1; 3, FLP-2; 4, FLP-3; 5, FLP-4; 6, FLP-5; 7, FLP-7; 8 , FLP-8; 9, FLP-10; 10, control plant. 


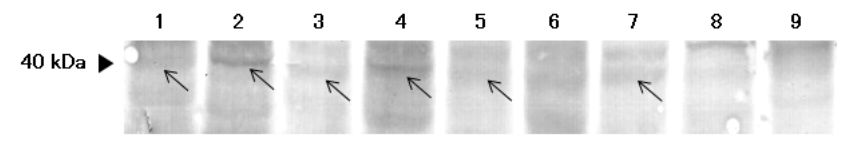

Figure 3: Immunological detection of LiP in the cell-free extracts of roots of LiP transgenic plants. Proteins were separated by SDS-PAGE and then transferred onto PVDF membrane. Lanes; 1 , extracts of FLP-1; 2, extracts of FLP-2; 3, extracts of FLP-3; 4, extracts of FLP-4; 5 , extracts of FLP-5; 6 , extracts of FLP-7; 7, extracts of FLP-8; 8, extracts of FLP-10; 9, extracts of control plant.

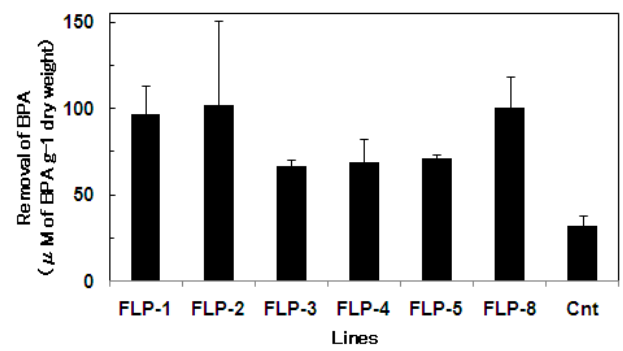

Figure 4: Removal of bisphenol A (BPA) by lignin peroxidase-producing transgenic tobacco plants. After hydroponic cultivation, as described in the Materials and Methods section, levels of BPA were analyzed by HPLC. The effluent was monitored at $278 \mathrm{~nm}$. The values shown are the average of results from three independent experiments. Cnt, Control plant. Error bars on the graph indicate standard deviations $(N=3)$.

peptide, the amino acid sequence of which was derived from $\mathrm{LiP}$ protein. The expected band for the LiP protein (approximately $40 \mathrm{kDa}$ ) was detected in the cell-free extracts of roots from transgenic plants (Figure 3). No signals were observed with extracts of the control plant, transgenic lines FLP-7 and FLP-10 at that size. The LiP transgenic plants, lines FLP-1, FLP-2, FLP-4 and FLP-8, showed a higher production of $\mathrm{LiP}$ protein than other LiP transgenic plants.

\section{Removal of BPA by LiP-producing hydroponically grown plants}

The six LiP-expressing transgenic plants (2 months old) were transferred to $100 \mathrm{~mL}$ of fresh MS liquid medium. After $1 \mathrm{wk}$ of incubation at $25^{\circ} \mathrm{C}, 10 \mu \mathrm{mol}$ of BPA was added to each hydrophonic culture. Figure 4 shows the disappearance of BPA catalyzed by the LiP-producing transgenic plants. The BPA removal ability of all tested LiP transgenic plants was found to be 2 - to 4 -fold higher than that of the control plant. The same transgenic plant lines were used in all the experiments, but different clones were used for the experiments. The growth conditions of the clones were not same exactly and these differences would be affected the decomposition rates and immuno signal intensities in the experiments.

However these results showed that flip-expressing plants were able to remove BPA more effectively that control plants during aqueous culture. All the Lip-producing transgenic plants eliminated BPA from aqueous culture, although we were unable to detect reaction products under our analytical conditions. The lignolytic enzyme system is nonspecific and utilizes a free radical-based reaction. The BPA may have been degraded or polymerized, as reported in some previous studies of lignolytic enzymes [3, 16-18].

Plants can grow autotrophcally, taking nutrients from sunlight, water, carbon dioxide and minerals, and spread their roots widely. Therefore, to achieve sustained decontamination of contaminated areas over the long term, phytoremediation technology can be a suitble tool. However, with chemicals that are hard to uptake or degrade, it is difficult to achieve effective removal. In this research, we focused on $\mathrm{LiP}$ gene derived from T. versicolor and introduced it into $N$. tabacum. LiP is a well-known enzyme that carries out direct and indirect oxidation of a number of environmental pollutants. However there have been no reports of LiP-expressing transgenic plants. We confirm herein the production of LiP protein and the BPA removal ability by transformants. Our results should help us to establish further better methods for the degradation and removal of hazardous chemicals from contaminated environments by transgenic plants.

\section{References}

1. Fernando T, Aust SD (1994) Biodegradation of toxic chemicals by whiterot fungi: Biological Degradation and Bioremediation of the Toxic Chemicals (Chaudhry GR, Ed.), Chapman \& Hall, London.

2. Reddy GVB, Gelpke MDS, Gold MH (1998) Degradation of 2,4,6-trichlorophenol by Phanerochaete chrysosporium: Involvement of reductive dechlorination. J Bacteriol 180:5159-5164

3. Hirano T, Honda Y, Watanabe T, Kuwahara M (2000) Degradation of bispehol $A$ by the lignin-degrading enzymes, manganese peroxidase, produced by the white-rot basidiomycete, Pleurotus ostreatus. Biosci Biotechnol Biochem 64:1958-1962.

4. Bizilly SP, Kim T, Kandasamy MK, Meagher RB (2003) Subcellular targeting of methylmercury lyase enhances its specific activity for organic mercury detoxification in plants. Plant Physiol 131:463-471.

5. Doty SL, Shang TQ, Wilson AM, Tangen J, Westergreen AD, et al. (2000) Enhanced metabolism of halogenated hydrocarbons in transgenic plants containing mammalian cytochrome P450 2E1. Proc. Natl Acad Sci USA 97:6287-6291

6. Gullner G, Komives T, Rennenberg H (2001) Enhanced tolerance of transgenic poplar plants overexpressing gamma-glutamylcysteine synthetase towards chloroacetanilide herbicides. J Exp Bot 52:971-979.

7. Novakova M, Mackova M, Chrastilova Z, Viktorova J, Szekeres M, et al (2009) Cloning the bacterial bphC gene into Nicotiana tabacum to improve the efficiency of PCB phytoremediation. Biotechnol Bioeng 102: 29-37.

8. limura Y, Ikeda S, Sonoki T, Hayakawa T, Kajita S, et al. (2002) Expression of a gene for Mn-peoxidase from Coriolus versicolor in transgenic tobacco generates potential tools for phytoremediation. Appl Microbiol Biotechnol. 59:246-251.

9. Sonoki T, Kajita S, Ikeda S, Uesugi M, Tatsumi K, et al. (2005) Transgenic tobacco expressing fungal laccase promotes the detoxification of environmenta pollutants. Appl Microbiol Biotechnol 67:138-142.

10. Jonsson L, Nyman PO (1992) Characterization of a lignin peroxidase gene from the white-rot fungus Trametes versicolor. Biochimie 74:77-182.

11. Reiser J, Walther IS, Fraefel C, Fiechter A (1993) Methods to investigate the expression of lignin peroxidase genes by the white rot fungus Phanerochaete chrysosporium. Appl Environ Microbiol 59:2897-2903.

12. Saloheimo M, Barajas V, Niku-Paavola ML, Knowles JKC (1989) A lignin peroxidase-encoding cDNA from the white-rot fungus Phlebia radiata: characterization and expression in Trichoderma reesei. Gene 85:343-351.

13. Ohara O, Dorit RL, Gilbert W (1989) One-sided prolymerase chain reaction: the amplification of cDNA. Proc Natl Acad Sci USA. 86:5673-5677.

14. Liang XW, Dron M, Schmid J, Dixon RA, Lamb CJ (1989) Developmental and environmental regulation of a phenylalanine ammonia-lyase-beta-glucronidase gene fusion in transgenic tobacco plants. Proc Natl Acad Sci USA 86: 9284 9288.

15. Murashige T, Skoog $F$ (1962) A revised medium for the rapid growth and bioassay with tobacco tissue cultures. Physiol Plant 15:473-497.

16. Fukuda T, Uchida H, Takashima Y, Uwajima T, Kawabata T, et al. (2001) Degradation of bisphenol A by purified laccase from Trametes villosa. Biochem Biophys Res Commun 284:704-706.

17. Tsutsumi $Y$, Haneda $T$, Nishida $T$ (2001) Removal of estrogenic activities of bisphenol $A$ and nonylphenol by oxidative enzymes from lignin degrading basidomycetes. Chemosphere 42:271-276.

18. Uchida H, Fukuda T, Miyamoto $H$, Kawabata T, Suzuki M, et al. (2001) Polymerization of bisphenol A by purified laccase from Trametes villosa. Biochem Biophys Res Commun. 287:355-358. 